\title{
External Jugular Vein Aneurysm with Thrombus Presenting as Neck Mass: A Case Report (Rare Case)
}

\author{
Anajar S*, Ansari R, Hassnaoui J, Rouadi S, Abada LR, Roubal M and Mahtar M \\ Department of ENT and Neck Surgery, Hospital on August 20, Casablanca, Morocco
}

${ }^{*}$ Corresponding author: Anajar S, Department of ENT and Neck Surgery, Hospital on August 20, Casablanca, Morocco, E-mail: anajar.said.med@gmail.com

Citation: Anajar S, Ansari R, Hassnaoui J, Rouadi S, Abada LR, et al. (2016) External Jugular Vein Aneurysm with Thrombus Presenting as Neck Mass: A Case Report (Rare Case). J Case Rep Stud 4(5): 506. doi: $10.15744 / 2348-9820.4 .506$

Received Date: Septemeber 03, 2016 Accepted Date: October 28, 2016 Published Date: October 31, 2016

\begin{abstract}
External jugular vein aneurysm with thrombosis presenting as neck swelling is a rare clinical entity and rarely encountered in routine clinical practice in otorhinolaryngology.

We present a case of a 52-year-old female with external jugular vein aneurysm presenting as a neck mass. Ultrasound of the neck and CT showed saccular dilation of the external jugular vein with thrombosis within the aneurysm. Saccular aneurysm of the external jugular vein is very uncommon and can lead to thrombotic complications with serious consequence.

Keywords: Saccular aneurysm; External jugular vein; Thrombosis
\end{abstract}

\section{Case Report}

A 52-year-old woman presented at our department with complaints of progressive swelling on left sternomastoidien region for 3 years. There was no history of preceding trauma, or cannulation of the vein and infusion of fluid for extended period and there was no history of difficulty in swallowing, change in voice or any nasal symptoms.

Physical examination revealed a $4 \times 3 \mathrm{~cm}$ soft, round, non-pulsatile, fluctuant swelling on the left sternocleidomastoidien region.

A 52-year-old woman presented at our department with complaints of progressive swelling on left sternomastoidien region for 3 years. There was no history of preceding trauma, or cannulation of the vein and infusion of fluid for extended period and there was no history of difficulty in swallowing, change in voice or any nasal symptoms.

The overlying skin over the swelling had no signs of inflammation. Swelling was mobile in horizontal plane. There was mild increase in the size of the swelling during Valsalva manoeuvre and during laughing. The swelling was mildly compressible and slip sign was negative. No bruit could be detected on auscultation over the swelling. There was no other swelling in the neck or on other parts of the body. Nasofibroscopy and rhinocavoscopy were normal.

Ultrasonography of the neck reported a thin-walled cystic mass on the left side abutting the left external jugular vein, Contrastenhanced computed tomography scan of the neck showed a focal area of dilatation of the left external jugular vein and enhancing oval-shaped swelling arising from the external jugular vein (Figure 1).

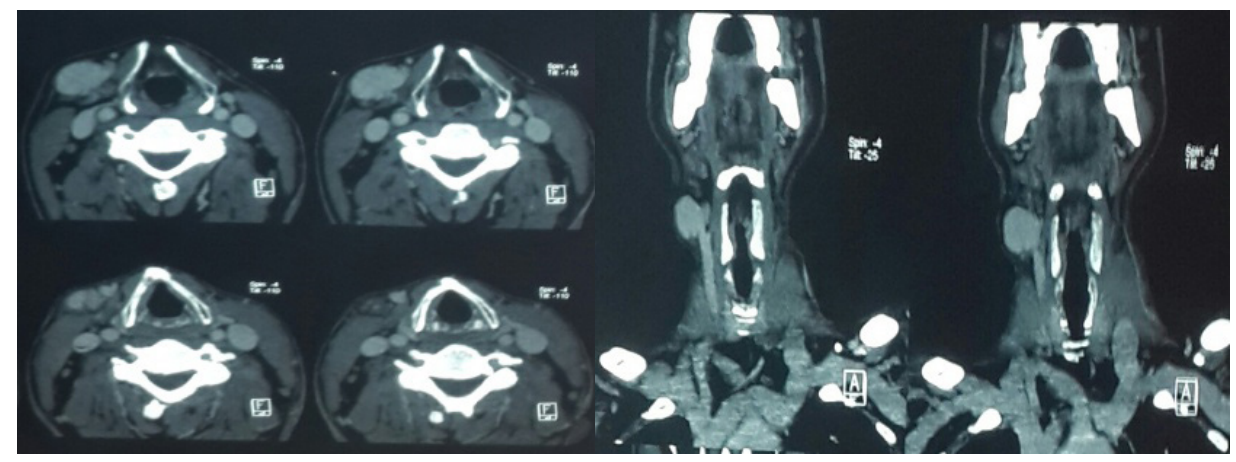

Figure 1: CT scan of the neck showing aneurysmal dilation of external jugular vein 
A decision to excise the swelling was made. Under general anesthesia, adhesion to the surrounding tissues was freed and the mass was excised after ligating the proximal and distal ends of the external jugular vein (Figure 2).

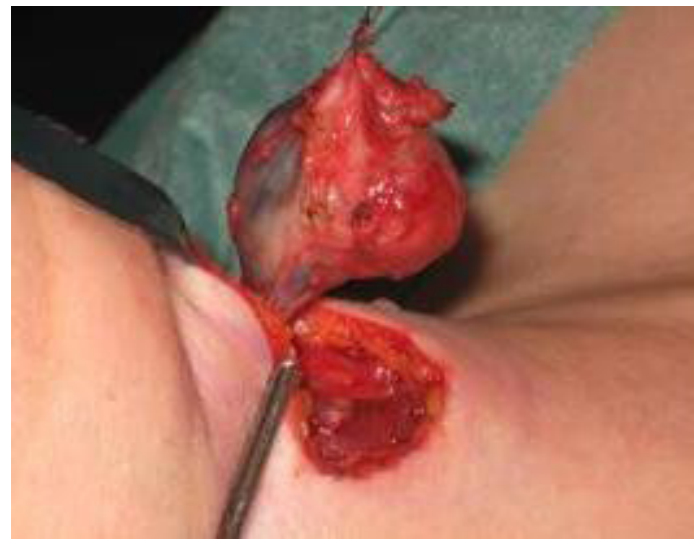

Figure 2: Resection of aneurysm with the excised mass

Histopathology showed a grossly dilated vein, $3 \times 2 \times 1 \mathrm{~cm}$, and the presence of a thrombus inside the dilated vein. Microscopically, it showed a dilated intact venous wall with marked reduction of smooth muscle cells in the media. A diagnosis of venous aneurysm was made.

\section{Discussion}

Venous aneurysms of the neck are rare due to low pressure in the vena cava system in the neck. The internal jugular vein is the most common vein involved [1], Aneurysm of the external jugular vein is rare and very few cases have been reported in the literature.

First described in the literature by Harris in 1928 [2]. Hischler suggested the term venous aneurysm similar to arterial aneurysm [3]. It can be congenital or acquired, common acquired causes of venous aneurysm include tumor, trauma, thoracic outlet syndrome, and iatrogenic causes.

Patients with external jugular venous aneurysm usually present with a soft, nonpulsatile, saccular or fusiform swelling in the neck, which increases in size on crying, straining, or with Valsalva maneuver. Few patients may complain of constricting sensation, choking, discoloration or discomfort in the neck.

Jugular venous aneurysms should be included in the differential diagnosis of any neck soft tissue mass when it can be easily confused with cavernous hemangioma, cystic hygroma, a laryngocele, a lymphocele, an enterogenous cyst, lymphadenopathy, thyroid swelling, a thyroglossal cyst, a dermoid cyst, and a branchial cleft cyst. 2 Enlargement of neck swelling during the Valsalva maneuver raises the suspicion of a laryngocele or jugular vein aneurysm. Absence of air in the mass on plain radiography eliminates a laryngocele. The most important complications include thrombus formation, thrombophlebitis, pulmonary embolism, and rupture [4].

The pathogenesis of venous aneurysm remains unknown. Endophlebosclerosis and endophlebohypertrophy are believed to be important factors in the development of venous aneurysm [5], Inflammation, degeneration, and increased venous pressure within the venous system could also lead to venous aneurysm [6].

CT angiography with Digital subtraction angiography is the gold standard in the diagnosis but venous color Doppler ultrasound is a noninvasive, accurate, and low-cost method for evaluation of venous aneurysms and is considered as the first-line study in the diagnosis of cervical venous aneurysms [7-10].

Jugular venous aneurysm may lead to thrombus formation due to stagnant and low pressure flow within the neck veins. There is also the risk of rupture of aneurysm by trauma to the neck, though arterial aneurysms are more prone to rupture [10].

Surgical excision is the treatment of choice in the management of venous aneurysm of the neck for the fear of risk of thrombosis, possible fear of rupture, and for cosmetic and esthetical reasons [10].

In our patient, surgery was performed due to an increased in size over the swelling which was suggestive of thrombus formation within the EJV aneurysm.

\section{Conclusion}

Jugular venous aneurysm is a rare entity, often asymptomatic. Thrombotic complications are the most frequent, CT angiography with Digital subtraction angiography is the gold standard in the diagnosis but venous color Doppler ultrasound study is also useful for the diagnosis of venous aneurysm and the treatment, when indicated, is surgical repair. 


\section{References}

1. Drakonaki EE, Symvoulakis EK, Fachouridi A, Kounalakis D, Tsafantakis E (2011) External jugular vein aneurysm presenting as a cervical mass. Int J Otolaryngol $10.1155 / 2011 / 485293$

2. Harris RI (1928) Congenital venous cyst of mediastinum. Ann Surg 88: 953-6.

3. Hilscher WM (1995) For the venous aneurysms ask [Zur frage der venosen aneurysmen]. Fortscher Röntgenstr 82: 244-7.

4. George BR, Hasan S, Naveen Kumar G, Tobook SMS, Dhinakar M (2010) A rare case of laryngocele in Omani male. Oman Med J 25: 157-9.

5. Schatz IJ, Fine G (1962) Venous aneurysms. N Engl J Med 266: 1310-2.

6. Azghari A, Belmir H, Kharroubi A, El Khaloufi S, El Idrissi R, et al. (2011) External jugular vein aneurysm: a rare cause of neck swelling. A report of three patients. J Mal Vasc 36: 395-8.

7. Zorn WG, Zorn TT, Van Bellen B (1981) Aneurysm of the anterior jugular vein. J Cardiovasc Surg (Torino) 22: 546-9.

8. Ekim H, Özen S (2002) Primary venous aneurysm of the external jugular vein. EJM 7: 24-5.

9. Bhalla AS, Gupta P, Mukund A, Kumar A, Gupta M (2012) Anamolous systemic artery to normal lung- A rare cause of hemoptysis in adults. Oman Med J 27: 319-22.

10. Fishman G, DeRowe A, Singhal V (2004) Congenital internal and external jugular venous aneurysms in a child. Br J Plast Surg 57: 165-7.

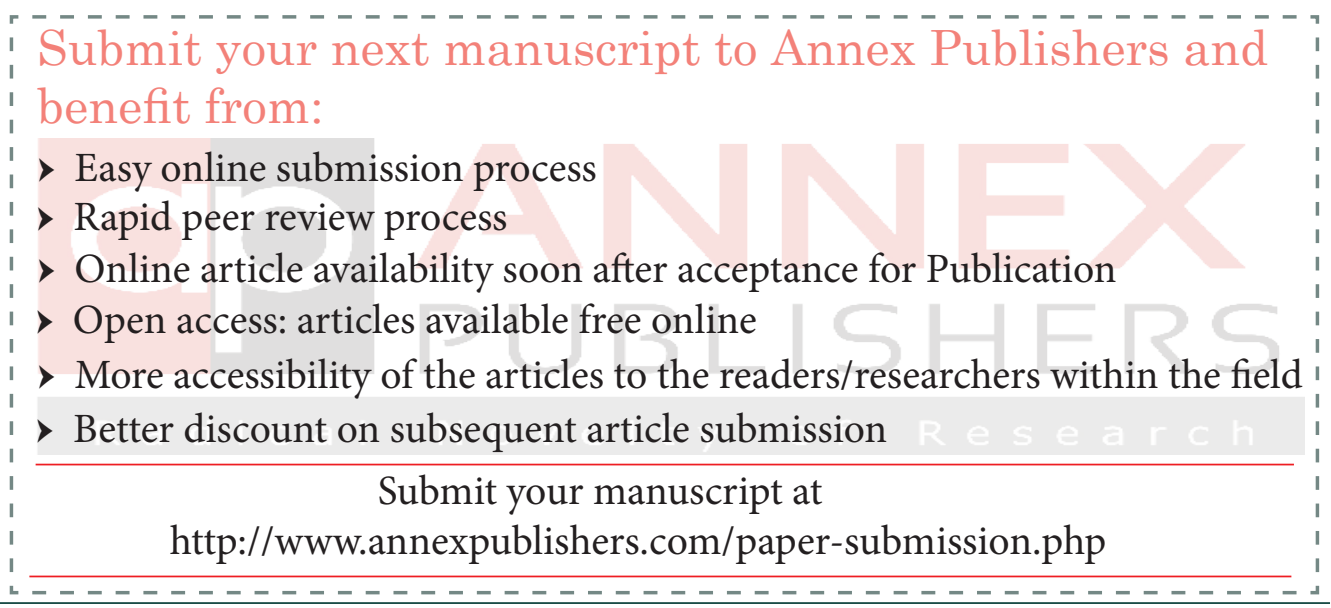

